\title{
Nerve biopsy and conduction studies in diabetic neuropathy
}

\author{
FRIEDRICH BEHSE, FRITZ B UCHTHAL, A N D \\ FR I T S CARLSEN
}

From the Laboratory of Clinical Neurophysiology, Rigshospitalet, the Institute of Neurophysiology, and Physical Laboratory II, University of Copenhagen, Denmark

SUMMARY Morphological findings in sural nerves were related to nerve conduction in 12 patients with diabetic neuropathy, five with mainly sensory involvement, four with severe, symmetrical sensory-motor polyneuropathy, and three with multiple mononeuropathy. All had loss of large and small myelinated and of unmyelinated fibres, even early in the disease; segmental remyelination was the most prominent myelin alteration in teased fibres, segmental demyelination was found in only a few fibres. Axonal degeneration and Schwann cell damage seem to proceed independently of each other. The relation between recorded conduction velocity and that expected from the diameter of the largest fibres indicated that slowing of 20 to $30 \%$ was due to causes other than fibre loss; a grossly diminished conduction velocity was caused mainly by fibre loss. Electrophysiological findings in the sural nerve were largely representative of findings in other nerves, though abnormalities were less marked in the median nerve. In half the endoneurial vessels from diabetic neuropathy the perivascular space was thickened or contained more layers of basal laminae than normal. The same abnormalities were found in one-quarter of the endoneurial vessels from other acquired neuropathies.

The slowing in conduction which characterises most sensory and motor nerves in diabetic neuropathy (Lamontagne and Buchthal, 1970) has been considered to be due to segmental demyelination (Gilliatt, 1966; Thomas and Lascelles, 1966; Chopra et al., 1969). The use of electron microscopy and teased fibre preparations have led to conflicting results and explanations: is demyelination or axonal loss the primary and main lesion, or does each develop independently of the other?

To clarify this problem, we have quantitated morphological findings in sural nerves and related them to abnormalities in conduction in patients with diabetic neuropathy.

\section{Patients}

Twelve consecutive patients with diabetes mellitus, abnormal glucose tolerance tests, and signs and symptoms of neuropathy were examined (Table). Near relatives of six patients had diabetes mellitus. In 11 the diabetes began in maturity $(>40$

Address for reprint requests: Professor F. Buchthal, Laboratory of Clinical Neurophysiology, Rigshospitalet, Copenhagen, Denmark. Accepted 2 June 1977 years). In four patients the metabolic disturbance was severe and in three of these poorly regulated. Other manifestations of diabetes were retinopathy (five patients), perforating ulcer of the leg (one patient), or other trophic changes (two patients). Four patients had hypertension, and none had signs of nephropathy or liver disease.

There was no evidence of other causes of the neuropathy than diabetes. In seven patients neurological signs and symptoms preceded or coincided with the diagnosis of diabetes mellitus. In five patients signs and symptoms of neuropathy were mainly sensory (diminished sensitivity to touch, pinprick, and vibration), the only clinical motor involvement being weakness and wasting of the extensor digitorum brevis muscle. Four patients had severe symmetrical weakness and wasting mainly in distal muscles of the lower limbs in addition to sensory impairment. In three patients weakness and wasting were localised to proximal or distal muscles of one leg; sensory impairment was bilateral in two. In all patients ankle jerks were absent or weak, knee jerks and tendon jerks in the arms were absent as well, with the exception of the five patients with mainly sensory 
Table Clinical data on 12 patients with diabetic neuropathy

\begin{tabular}{|c|c|c|c|c|c|c|c|c|c|}
\hline Patient & $\begin{array}{l}\text { Age } \\
(y r)\end{array}$ & Sex & $\begin{array}{l}\text { Diabetes me } \\
\text { Duration }\end{array}$ & us & Treatment & $\begin{array}{l}\text { Duration } \\
\text { of neuropathy }\end{array}$ & $\begin{array}{l}\text { Senso } \\
\text { Feet }\end{array}$ & $\begin{array}{l}\text { irment } \\
\text { Hands }\end{array}$ & Weakness \\
\hline \multicolumn{10}{|c|}{ Sensory neuropathy } \\
\hline 124 & 51 & $\mathbf{F}$ & recently & mild & diet & $1 \frac{1}{2}$ years & + & 0 & none \\
\hline 191 & 56 & $\mathrm{~F}$ & 2 years & mild & diet & 2 years & + & 0 & none \\
\hline 229 & 55 & $\mathbf{M}$ & 5 months & mild & diet & 5 months & + & 0 & none \\
\hline 240 & 43 & $\mathbf{F}$ & 23 years & severe & insulin & 1 year & + & + & none \\
\hline \multicolumn{10}{|c|}{ Symmetrical sensory-motor neuropathy } \\
\hline 28 & 71 & $\mathrm{~F}$ & 1 year & severe & insulin & 6 months & + & 0 & prox. + dist. \\
\hline 166 & 51 & $\mathbf{F}$ & 5 years & mild & oral & 2 years & - & + & distal \\
\hline 198 & 67 & $\mathbf{F}$ & 1 year & mild & diet & 1 year & $\div$ & + & distal \\
\hline 228 & 71 & $\mathbf{M}$ & $\geq 14$ years & mild & diet & 14 years & + & + & distal \\
\hline \multicolumn{10}{|c|}{ Multiple mononeuropathy } \\
\hline 81 & 58 & $\mathrm{~F}$ & 15 years & mild & oral & 6 months & $(+)$ & 0 & left quadr. \\
\hline 222 & 70 & $\mathbf{M}$ & 12 years & severe & insulin & 1 year & + & 0 & left leg \\
\hline 225 & 55 & $\mathbf{M}$ & recently & mild & diet & 8 months & + & 0 & left ant. tib. \\
\hline
\end{tabular}

involvement. All 12 patients complained of paraesthesia, and nine complained of severe pain in the legs. The spinal fluid protein was normal.

Seven patients were re-examined one to eight years after the first study. One of three patients with severe sensory-motor involvement had improved and would be classified as mainly sensory neuropathy at the second study; conduction velocity was still severely slowed. The neuropathy of the other six patients (two with symmetrical sensory-motor, two with mainly sensory neuropathy, and two with multiple mononeuropathy) had progressed slightly with respect to sensory and improved in five with respect to motor impairment; they would still be classified as at the first examination; conduction velocities were as when the patients were first seen, and amplitudes of the sensory potentials had diminished further. In one patient with multiple mononeuropathy a paralysis of the distal segment of the median nerve had developed suddenly, simulating a carpal tunnel syndrome, similar to the patient of Gilliatt and Willison (1962). There was, however, no pain.

\section{Method}

SENSORY AND MOTOR NERVE CONDUCTION (Behse and Buchthal, 1971).

Sensory conduction was determined along the sural nerve (lateral malleolus to $120 \mathrm{~mm}$ proximal to it or to the popliteal fossa), along the superficial peroneal nerve (from the superior retinaculum at the ankle to the capitulum fibulae), along the saphenous nerve (from the medial epicondyle to the inguinal ligament), along the distal portion of the posterior tibial nerve (from toe I to the medial malleolus), and along the distal segments of the median nerve (from digits I and III to the wrist). Sensory nerve action potentials which were less than $3 \mu \mathrm{V}$ were recorded by electronic averaging of 500-2000 potentials (Buchthal and Rosenfalck, 1966).

Motor nerve conduction and distal and proximal latencies were determined along the deep peroneal, the femoral, the posterior tibial, and the median nerves.

\section{ELECTROMYOGRAPHY}

Electromyography was performed in two to five distal and proximal muscles in the lower and upper limbs.

\section{NERVE BIOPSY}

Thirty millimetres of the sural nerve were removed in toto, just proximal to the lateral malleolus, and fixed in $2 \%$ buffered isotonic glutaraldehyde $(36 \mathrm{~h})$. For the preparation of teased fibres, a $10 \mathrm{~mm}$ length was postfixed in $1 \%$ buffered osmium tetroxide $(4 \mathrm{~h})$ and stored in $0.2 \mathrm{M}$ sucrose. For light and electron microscopy the specimen was post-fixed in $1 \%$ buffered osmium tetroxide $(2 \mathrm{~h})$, dehydrated in graded concentrations of ethanol and embedded in Epon 812 (Behse et al., 1974). Transverse sections (3-5 $\mu \mathrm{m}$ thick) for light microscopy were stained with $1 \%$ paraphenylene-diamine (Holländer and Vaaland, 1968), and ultrathin sections for electron microscopy were stained with uranyl acetate and lead citrate (Reynolds, 1963).

Light microscopy In each biopsy specimen the transverse endoneurial area was measured, and in an area of $0.4-0.6 \mathrm{~mm}^{2}$, sampled from all fascicles, the total number and size distribution of myelinated fibres and the number of groups of 
three or more regenerating fibres ('clusters') were determined (Behse et al., 1972, 1974).

Electron microscopy An area of 10000 $20000 \mu \mathrm{m}^{2}$, sampled from three different fascicles, was analysed at a final magnification of $\times 10000$ 12000 . The incidence was determined of fibres with abnormalities in the fine structure of the axon or of the myelin sheath, of bands of Büngner, and of onion-bulb formations. Unmyelinated fibres were identified by criteria described elsewhere (Behse et al., 1975); their number and size distribution, the incidence of degenerating fibres, characterised by loss of axonal organelles, and the number of Schwann cell subunits containing or devoid of unmyelinated fibres were determined.

Finally, we measured the thickness of the perivascular space of the endoneurial vessels (final magnification $\times 10000-20000$ ). To avoid errors due to oblique sectioning, the smallest thickness was measured from the outer membrane of the endothelial cells to the outer concentric layer of basal laminae. Measurements across the nuclear region of pericytes were avoided. We did not measure the thickness of the individual layer of basal laminae (Bischoff, 1968).

Findings from electron microscopy were compared with those in six nerves from controls and, with respect to endoneurial vessels, with findings in nerves from 13 patients with other types of acquired neuropathy.

Teased fibres In nine nerves 34 to 73 myelinated fibres, more than $7 \mu \mathrm{m}$ in diameter, were teased in $60 \%$ glycerol (Vizoso and Young, 1948). The incidence of the following abnormalities was determined from micrographs at a magnification of $\times 160-200$ for measurement of internodal length, and of $\times 800$ for measurement of diameter (Behse and Buchthal, 1977b): (a) segmental demyelination; (b) widening of the nodal gap to more than $10 \mu \mathrm{m}$ and paranodal demyelination over a length of up to $300 \mu \mathrm{m}$; (c) fibres which had internodes of normal length, containing some internodes with an abnormally thin myelin sheath; (d) segmental remyelination; two or more short, often thinly myelinated segments between segments of normal length; (e) solitary intercalated segments; (f) regenerated fibres-all internodal segments were short $(0.2-0.6 \mathrm{~mm})$ and had a disproportionately thick diameter.

\section{OTHER TESTS}

Glucose in blood and urine, glucose tolerance test, liver function tests, and investigation of the cerebrospinal fluid were performed by standard techniques.

\section{Results}

NERVE CONDUCTION

In $76 \%$ of 25 sensory nerves examined in the lower extremities, and in $30 \%$ of 20 branches of median nerves, conduction velocity was slowed. In motor nerves slowing in conduction occurred as often along the nerves of the lower as along those of the upper extremities. Sensory conduction velocity was normal or slightly slowed in patients with only sensory involvement and in patients with multiple mononeuropathy; in two patients with severe sensory and motor involvement, slowing was marked (to less than $60 \%$ of normal, that is, less than $30-35 \mathrm{~m} / \mathrm{s})$. Slowing of motor conduction also tended to be more marked in patients with sensory-motor involvement (Fig. 1).

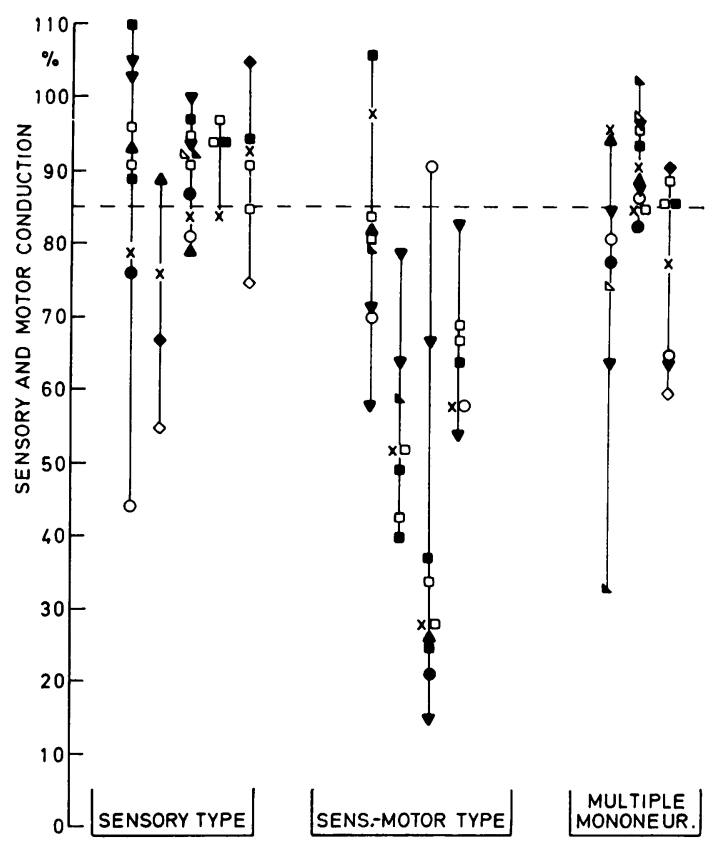

Fig. 1 Sensory and motor nerve conduction in patients with the three types of diabetic neuropathy. Conduction velocity is given as a percentage of the normal average, matched for age; motor latencies are given as reciprocal latencies. Each vertical line connects findings in different nerves in the individual patient; - - - =lower $95 \%$ confidence limit of normal. Symbols: Sensory nerves: sural $(X)$, superficial peroneal $(\bigcirc)$, posterior tibial $(\diamond)$, saphenous $(\Delta)$, median ( $\square$, digits I and III). Motor nerves, velocity: deep peroneal (O). Motor latencies: $m$. tibialis anterior and $m$. peroneus longus $(\nabla), m$. extensor digitorum brevis ( $\triangle), m$. flexor hallucis brevis $(\diamond)$, m. quadriceps ( $), m$. abductor pollicis brevis $(\mathbf{G})$. 
AMPLITUDE OF THE SENSORY ACTION POTENTIAL

In $65 \%$ of 48 nerves examined in the upper and lower extremities the amplitude of the sensory nerve action potentials was diminished. About half the potentials were split up into many components. The reduction in amplitude was most marked in patients with severe sensory and motor involvement (amplitudes $<10 \%$ of normal; in the sural nerve less than $1 \mu \mathrm{V}$, Fig. 2).

The amplitude of the evoked muscle action potentials was normal in patients with mainly sensory involvement and diminished in nearly all muscles of patients with severe sensory-motor involvement and in paretic muscles of patients with multiple mononeuropathy.

\section{ELECTROMYOGRAPHY}

The electromyogram was investigated quantitatively in 37 muscles. In patients with sensorymotor neuropathy, muscles of the lower and upper limbs showed marked signs of denervation (loss of motor units, low amplitude of the recruitment pattern, fibrillation potentials, and positive sharp waves), and of reinnervation (increased incidence of long polyphasic potentials and prolonged duration of motor unit potentials). The same degree of denervation was found in paretic muscles of patients with multiple mononeuropathy, but reinnervation was less prominent.

In patients with sensory neuropathy, electromyographic abnormalities were more prominent in the lower than in the upper limbs. Moderate to severe loss of motor units was present in nearly all muscles, even in those with clinically normal force. Fibrillation potentials were rare, and reinnervation was less pronounced than in the other types of diabetic neuropathy.

\section{BIOPSY FINDINGS IN THE SURAL NERVE}

Endoneurial area The endoneurial area was normal in eight and increased in four nerves (Fig. 3). Onion-bulb formations were absent both in light and electron microscopy, even in the nerves with a marked increase in endoneurial area.

Myelinated fibres In 10 of the 12 nerves, the number of myelinated fibres was diminished (Fig. 3 ). In the nerves from patients with mainly sensory neuropathy and with multiple mononeuropathy the number of fibres of large $(>7 \mu \mathrm{m})$ and small $(<7 \mu \mathrm{m})$ diameter was reduced equally. Three of the four nerves from patients with symmetrical sensory-motor involvement had lost most of their large fibres.

Degenerated fibres were found in all nerves, their incidence was highest in the nerves with the greatest fibre loss. The many bands of Büngner

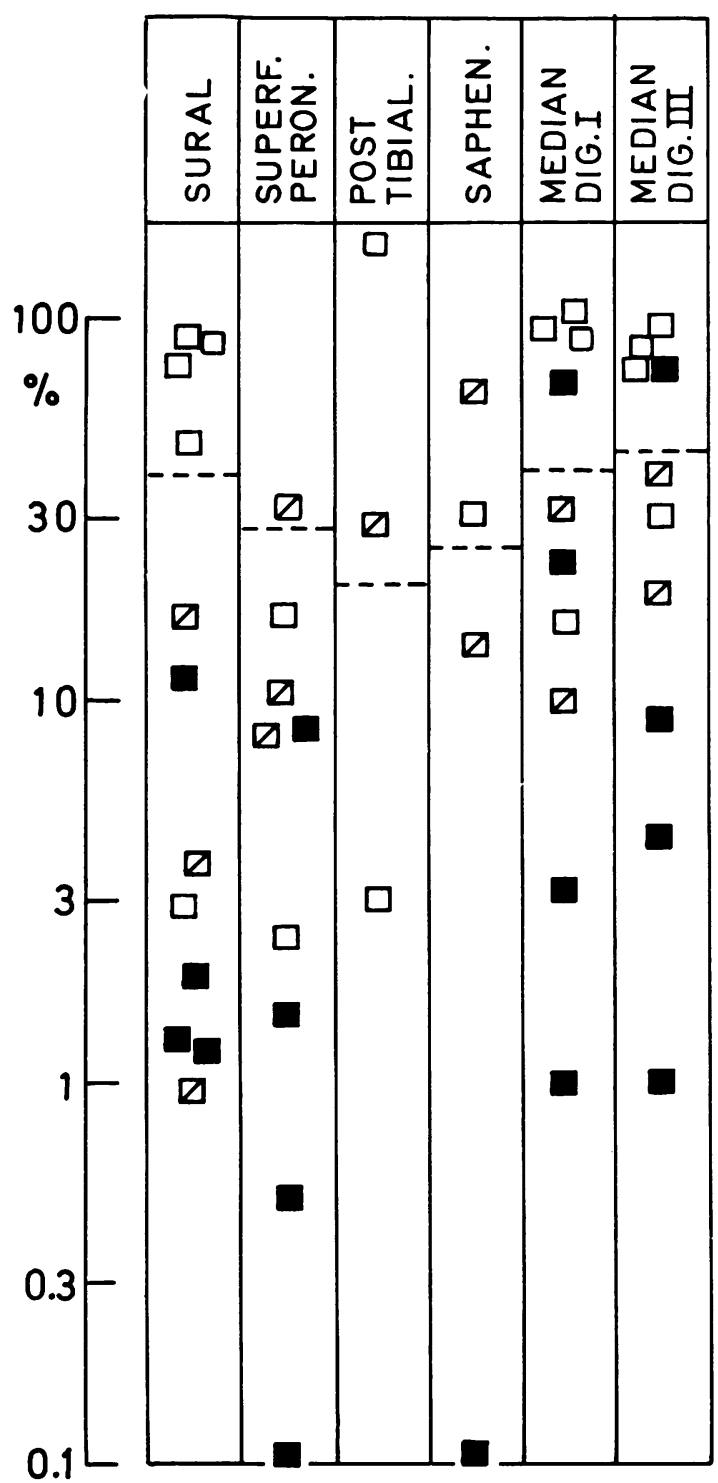

Fig. 2 Amplitude of sensory nerve action potentials in the different nerves as a percentage of the normal average matched for age (log scale); - .-- =lower $95 \%$ confidence limits of normal. Types of neuropathy: sensory ( $\square)$, sensory-motor $(\square)$, multiple mononeuropathy (ロ).

(2000-3000 per nerve) in patients with neuropathy of short duration indicate axonal loss to be an early abnormality. With longer duration of the neuropathy, the number of bands of Büngner decreased to $100-1000$, disproportionately few in relation to the fibre loss. Regeneration of nerve 


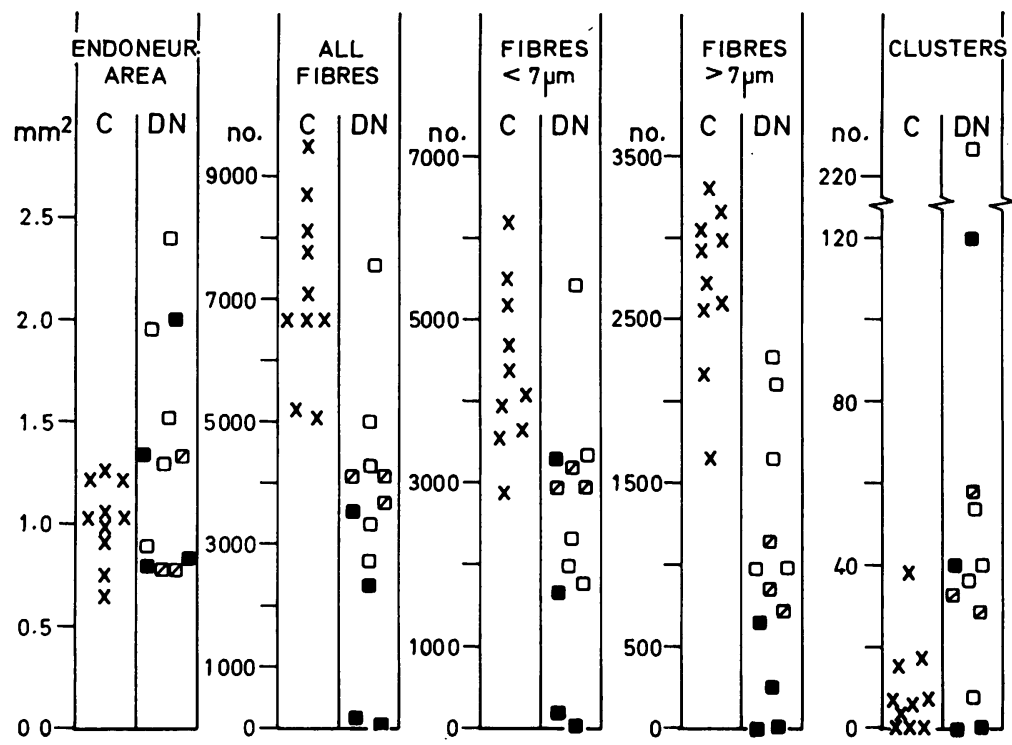

Fig. 3 Endoneurial area, number of myelinated fibres and of clusters of regenerating fibres in sural nerves from patients with diabetic neuropathy $(D N)$ and in controls $(C, \times)$. Symbols for the different types of diabetic neuropathy as in Fig. 2. fibres, evidenced by the presence of clusters, was seen in nine nerves.

In nerves of patients with sensory neuropathy (Fig. 4, right) and with multiple mononeuropathy (Fig. 4, left), the histogram of fibre diameters was bimodal, and in the four nerves from patients with sensory-motor neuropathy the histogram was unimodal or unimodal and skew.

Conduction velocity as related to fibre diameter Conduction velocity and the diameter of myelinated fibres are proportional and maximum conduction velocity can be calculated from the diameter of the largest fibres by the conversion factor (Gasser and Erlanger, 1927), found in the human sural nerve to be $4.3 \pm 0.1$ (Buchthal et al., 1975). In all diabetic nerves except one the conduction velocity was lower than to be expected from the fibre diameter (Fig. 5). In six nerves it deviated at most $20 \%$, exceeding slightly the largest deviation observed in nerves from controls. In five nerves the recorded velocity was $20-30 \%$ slower than to be expected from the fibre diameter, the additional slowing being relatively the same whether the recorded velocity was $15 \mathrm{~m} / \mathrm{s}$ or $42 \mathrm{~m} / \mathrm{s}$.

Teased fibres One or the other abnormality in the myelin sheath was found in every nerve; abnormalities were present in $35-80 \%$ of the fibres, as compared with at most $30 \%$ in control nerves. As to the type of abnormality (Fig. 6), fibres with demyelinated segments were found in the nerves of those two patients with neuropathy of the shortest duration; in all it occurred in only eight of 502 teased fibres. Paranodal demyelination was also scarce, occurring in three nerves, in all in $\mathbf{1 7}$ fibres. Segmental remyelination was the most frequent abnormality; it was seen in all but one nerve and occurred in $20-40 \%$ of teased fibres. Usually one single internodal segment per teased fibre was replaced by two to four short remyelinated segments. Other abnormalities of the myelin sheath (solitary intercalated segments and fibres which had some segments with a disproportionately thin myelin sheath), though present in most nerves, occurred in only a small proportion of teased fibres. Solitary intercalated segments were usually found at a single site of teased fibres. One-sixth of the fibres with segmental remyelination had in addition one or more solitary intercalated segments. Finally, few nerves contained some fibres with abnormal Ranvier nodes, probably indicating local repair (Thomas and Lascelles, 1966). Only two nerves had a marked number of regenerated fibres.

Conduction velocity related to myelin abnormalities In the nine nerves from patients with diabetic neuropathy, the incidence of abnormalities in the myelin sheath was not related to conduction velocity, whether the proportion of abnormalities was taken of the number of teased fibres or of the number of internodal segments. However, when 91 nerves were pooled (including those from diabetic neuropathy), conduction velocity decreased with increasing incidence of myelin abnormalities $(P<0.001)$. These nerves were from control subjects and from patients with various types of acquired and degenerative neuropathies (unpub- 

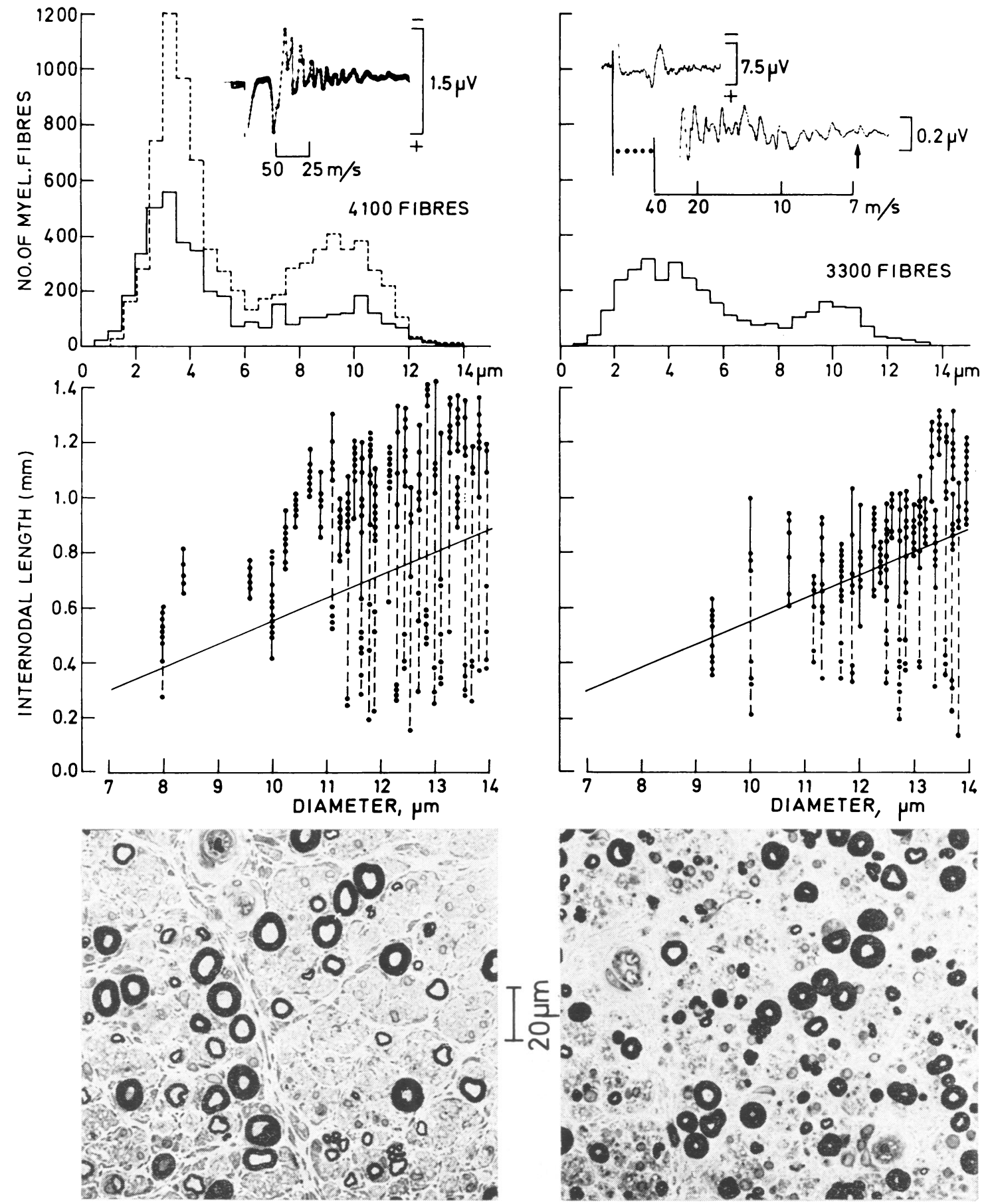

Fig. 4 Sensory nerve conduction and histological findings in myelinated fibres of the sural nerve in diabetic neuropathy. Left: multiple mononeuropathy (patient 81, Table), right: neuropathy of the mainly sensory type (patient 124, Table). Insets: sensory nerve action potential; left: conduction velocity was normal, the amplitude was diminished and the potential was split up in shape; right: maximum and minimum conduction velocities were slowed (lower trace recorded at increased amplification); the amplitude was normal. Above: the number of myelinated fibres was diminished in both nerves; the bimodal distribution of fibre diameters was retained. Dashed line shows distribution of fibre diameters in normal nerve. A representative sample of the cross-section for each nerve is shown below. Middle: internodal length as a function of the diameter of the longest internode, presented as suggested by Fullerton et al. (1965); 30 of 73 teased fibres (left) and 25 of 55 teased fibres (right) are drawn. Normal segments are connected by full vertical lines, and remyelinated segments by dashed lines. Oblique line represents the lower $95 \%$ confidence limit of normal internodal length. Paranodal and segmental remyelination was present in $38 \%$ (left) and $49 \%$ (right) of teased fibres. 


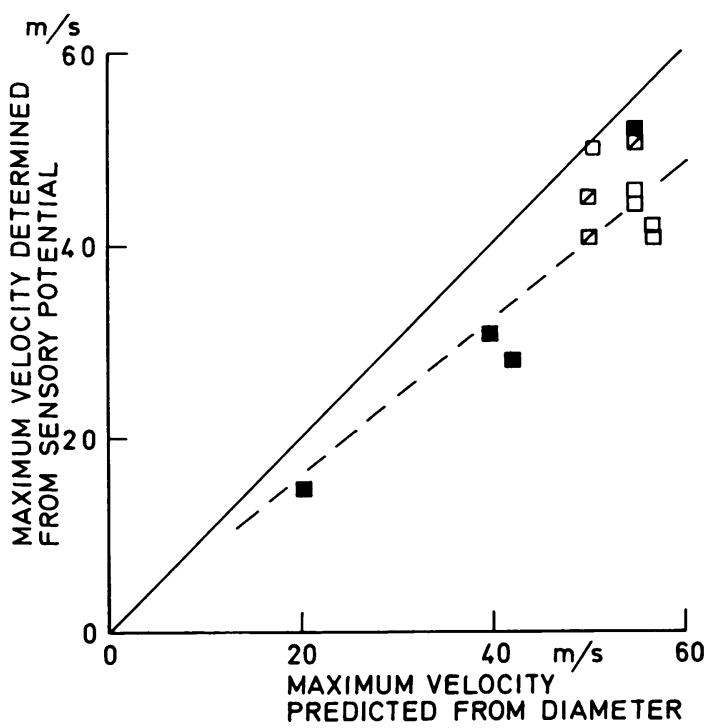

Fig. 5 Maximum conduction velocity along sural nerve determined from the sensory action potential, as a function of the velocity predicted from diameter of the largest myelinated fibres. Full line indicates equality between recorded and predicted velocity, dashed line represents a $20 \%$ slower recorded than predicted velocity. Symbols for the different types of diabetic neuropathy as in Fig. 2.

lished data). The large scatter in the relation between myelin damage and conduction velocity may be due in part to the fact that conduction velocity was determined over a length of $120 \mathrm{~mm}$, whereas abnormalities in teased fibres were determined over at most $10 \mathrm{~mm}$. When abnormalities were counted over half the length of the teased fibre, their incidence decreased by about one-third. The incidence of abnormalities would probably increase if a representative number of fibres could have been teased over, for example, $20 \mathrm{~mm}$.

Electron microscopy of myelinated nerve fibres The cross-sectional area investigated contained 542 myelinated fibres. Only two fibres of one nerve showed loss of axonal organelles, indicating the beginning of axonal degeneration. Signs of demyelination, present in two nerves, were found in less than $1 \%$; signs of incipient remyelination (disproportionately thin myelin sheath) were present in only three nerves, in $2 \%$ of the fibres examined. Otherwise, myelin thickness was normal relative to the axonal diameter.

Unmyelinated fibres Unmyelinated fibres and their Schwann cells were assessed in 10 nerves. The most severe abnormalities were found in the seven nerves from patients with sensory or sensory-
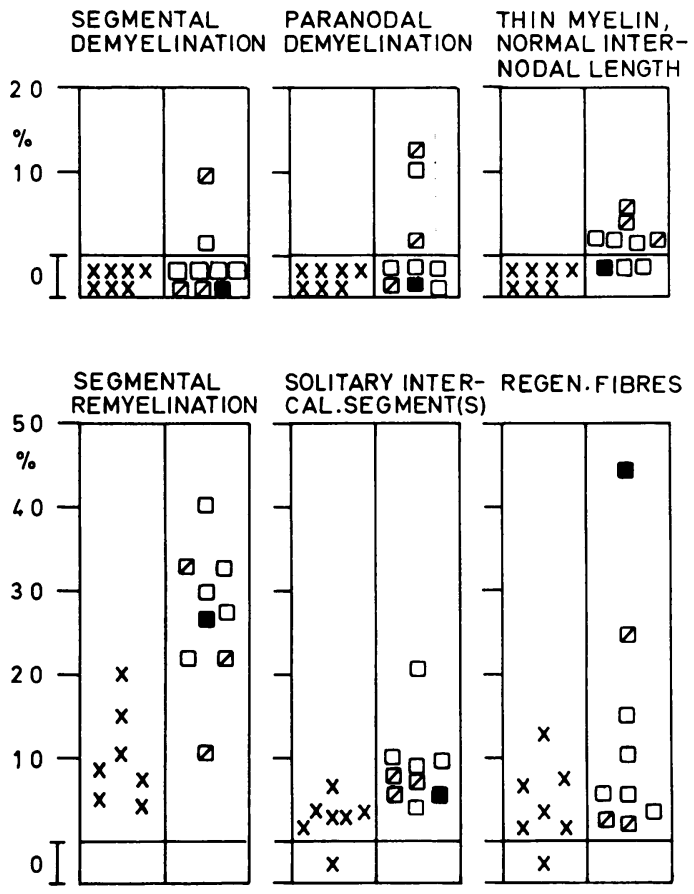

Fig. 6 Incidence of fibres with myelin abnormalities and of regenerated fibres among teased fibres from sural nerves of patients with diabetic neuropathy, and from controls $(X)$. Symbols for the different types of diabetic neuropathy as in Fig. 2.

motor neuropathy: a diminished number of unmyelinated fibres (three nerves), an increased number of fibres undergoing degeneration (four nerves), and a markedly increased number of Schwann cell subunits devoid of axons (six nerves). Two of the three nerves from patients with multiple mononeuropathy had one or the other abnormality in unmyelinated fibres or their Schwann cells, though abnormalities were mild. In all 10 nerves, the mean diameter and the size distribution of unmyelinated fibres were normal.

Endoneurial vessels The thickness of the perivascular space and the number of layers of basal laminae (Fig. 7) were determined in nine nerves of patients with diabetic neuropathy, and compared with seven controls and with 13 nerves of patients with other types of acquired neuropathy. Because of indistinct separation of the individual layers (absence of connective tissue between them), their number could not be counted in six vessels from patients with diabetic neuropathy and in two vessels from control subjects.

In control subjects, the thickness of the perivascular space ranged from 1-4 $\mu \mathrm{m}$, and it contained 

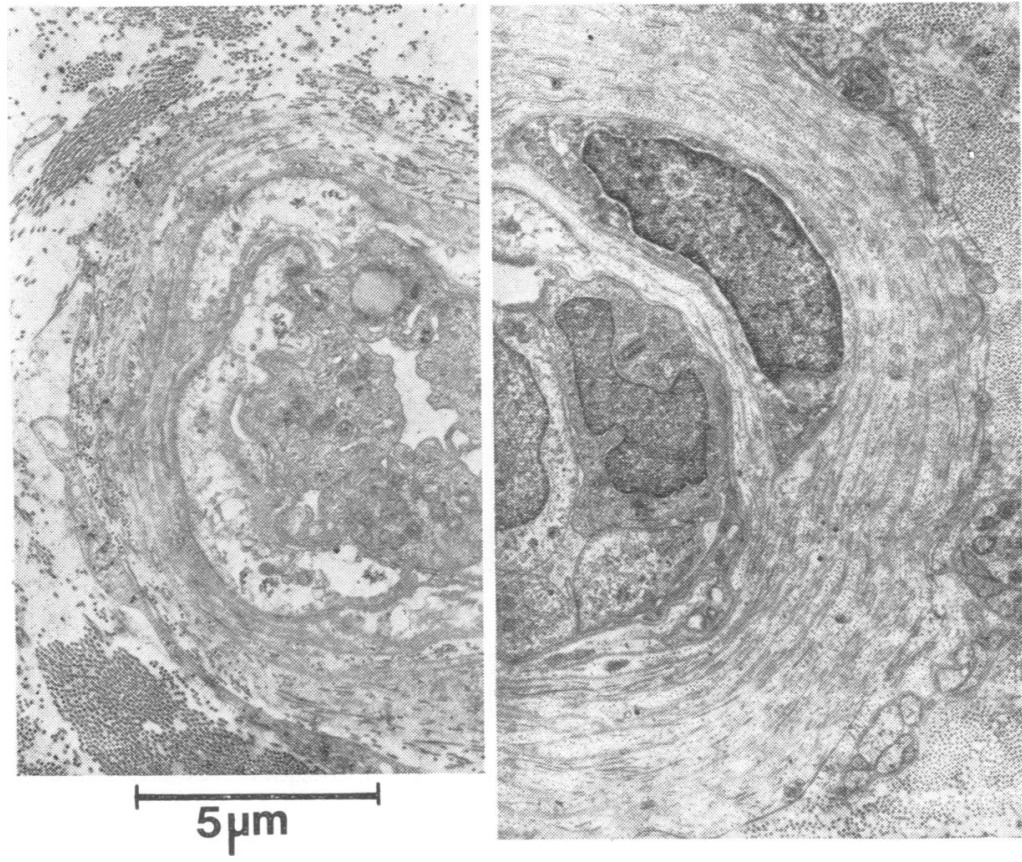

Fig. 7 Electron micrographs of endoneurial vessels. Left, from normal nerve; right, from nerve of a patient with diabetic neuropathy. Note increased thickness of pericapillary space and increased number of concentric layers of basal laminae interwoven with collagen fibrils in diabetic neuropathy. five to 10 concentric layers of basal laminae or of fragments of basal laminae interwoven with layers of collagen fibrils (Fig. 7). In seven vessels from nerves of patients with diabetic neuropathy the diameter of the perivascular space was increased (Fig. 8), and nine vessels contained 11-17 layers of basal laminae; in all, half the vessels showed either one abnormality or the other, or both. Similar abnormalities were found in one-quarter of the vessels from nerves of patients with other types of acquired neuropathy.

\section{Discussion}

In most early studies, loss of myelinated fibres was considered to be the main pathology of diabetic neuropathy (Greenbaum et al., 1964). Thomas and Lascelles (1965, 1966) found segmental demyelination in teased fibres of all nerves, whereas axonal loss occurred particularly in severe chronic cases. They considered it an open question whether the axonal loss was secondary to segmental demyelination or occurred independently. Since demyelination but not axonal loss was found in diabetics without neuropathy, Chopra $e t$ al. (1969) believed segmental demyelination to be the primary abnormality. This confirmed the view of Bischoff (1968) that a metabolic Schwann cell lesion is the primary defect in diabetic neuropathy. However, neuropathy that occurred early in the course of diabetes was associated with axonal degeneration (Bischoff, 1973). Thomas and Eliassen (1975), in their recent review, considered it unsettled whether demyelination is the primary lesion in diabetic neuropathy or is secondary to axonal degeneration. Our findings are compatible with the assumption that demyelination and axonal loss are independent processes.

As to demyelination, the most frequent abnormality in teased fibres was segmental remyelination, though it was far less frequent than in the hypertrophic type of peroneal muscular atrophy (Behse and Buchthal, 1977a). Onion-bulb formations were absent both on light and electron microscopy; they were found by Ballin and Thomas (1968) in seven of 10 biopsies from patients with diabetic neuropathy. Segmental remyelination was more frequent than in those neuropathies with axonal loss as the main pathology (Behse and Buchthal, 1977a, b). Paranodal myelin damage is an early change both in axonal degeneration and in segmental demyelination (Ballin and Thomas, 1969). When it is secondary to axonal degeneration, myelin damage tends to occur at multiple sites along certain fibres (Dyck et al., 1971). In our material paranodal or segmental de- or remyelination of multiple sites occurred in two of nine nerves in half the teased fibres with myelin abnormalities. In contrast to findings of Bischoff (1973), we found de- or remyelination also in those 

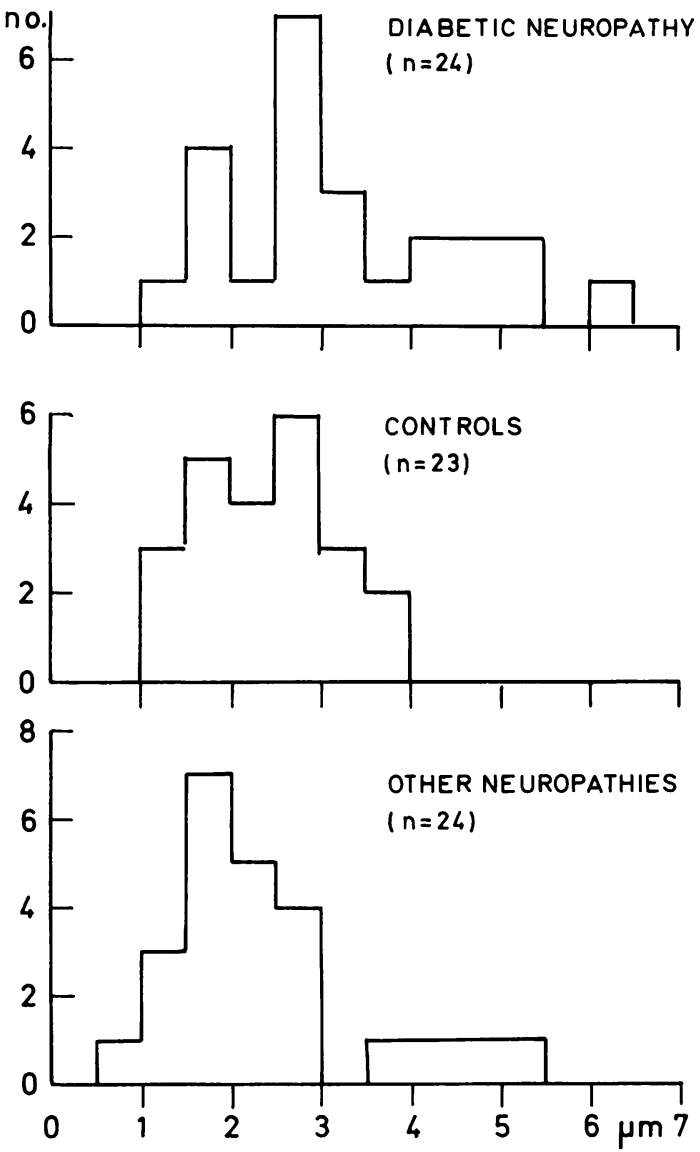

Fig. 8 Number of endoneurial vessels with different thickness of the perivascular space in nine nerves of patients with diabetic neuropathy, seven controls, and 13 nerves of patients with other types of acquired neuropathy. $n=$ number of vessels.

patients in whom signs and symptoms of neuropathy preceded the diagnosis of diabetes.

As to axonal degeneration, all nerves showed signs of loss of myelinated and unmyelinated fibres, even in patients with neuropathy of the shortest duration. Our findings agree with the diminished density of myelinated fibres of all sizes, reported by Chopra and Hurwitz (1969) in eight of nine patients with sensory-motor neuropathy. Fibre loss was also evident from the low amplitude of evoked nerve and muscle action potentials and from the loss of many motor unit potentials in the electromyogram. In clinically non-involved nerves of patients with multiple mononeuropathy, histological and electrophysiological abnormalities were similar to those de- scribed by Williams and Mayer (1976), and were as marked as in nerves of patients of the sensory type of neuropathy.

Brown et al. (1976) thought the pain in three diabetic patients with sensory neuropathy to be due to a disproportionate loss of small myelinated fibres and a disproportionate increase in the number of small unmyelinated fibres. This 'smallfibre neuropathy' was not found in our patients with sensory neuropathy who complained of severe pain.

In most sural nerves, the conduction velocity was $10-30 \%$ slower than to be expected from the diameter of the largest myelinated fibres. This slowing was relatively the same whether the largest fibres were lost or preserved. The additional slowing was probably due in part to myelin damage. It is unsettled to what extent other causes play a role-for example, abnormalities without morphological concomitants as assumed in experimental diabetes (Sharma and Thomas, 1974).

The fact that many clinically normal muscles in the mainly sensory type of neuropathy had electromyographic abnormalities raises the question whether the clinical differences between the sensory and the sensory-motor types reflect a difference in severity rather than in type. Fibre loss was more pronounced in patients with the sensory-motor than in those with the sensory type, as was the diminution in the amplitude of the sensory action potentials and the slowing in nerve conduction velocity. But the relation between the recorded velocity and the velocity expected from diameter of the largest fibres was the same, indicating that there is no evidence for different mechanisms that cause the abnormalities in conduction in the two types. Moreover, one of the patients with the sensory-motor type would have been classified as having the sensory type one year after the first study.

Compared with nerves from control subjects, half the endoneurial vessels from diabetic neuropathy had thickening of the perivascular space or an increased number of concentric layers of basal laminae. Similar observations were reported by Bischoff $(1965,1973)$, who found, in addition, an increase in the thickness of the individual basal laminae, which we did not measure in our patients. Some of the changes in vessels from diabetic nerve may have been overrated, since the perivascular space of endoneurial vessels has been assumed to be normally as thin as around intramuscular vessels (Garcin and Lapresle, 1968; Arné et al., 1972; Vital et al., 1973). In fact, in controls the perivascular space around endoneurial vessels was 
thicker than around intramuscular vessels. The same abnormalities as in diabetic neuropathy were present in one-quarter of the endoneurial vessels in other types of acquired neuropathies.

We are indebted to the Departments of Neuromedicine, Neurosurgery, and Medicine (TA), Rigshospitalet, to the Departments of Neurology of the Municipal Hospital and Bispebjerg Hospital, Copenhagen, the Frederiksborg County Hospital, Hillerød, the Hvidøre Hospital for Diabetics, Copenhagen, and the Department of Rheumatology, Copenhagen County Hospital, Hvidovre, for permission to examine patients under their care, and to the staff of the Department of Neurosurgery, Rigshospitalet, Copenhagen, for performing the sural nerve biopsies. The work was supported by grants from the Muscular Dystrophy Associations of America Inc. and the Michaelsen Foundation, Copenhagen.

\section{References}

Arné, L., Vital, Cl., Vallat, J.-M., Yung. A., Leblanc, M., and Martin, F. (1972). Neuropathie périphérique diabétique. Étucle anatomo-clinique avec ultrastructure d'une biopsie nerveuse. Revue Neurologique, 126, 115-126.

Ballin. R. H. M., and Thomas, P. K. (1968). Hypertrophic changes in cliabetic neuropathy. Acta Neuropathologica (Berlin), 11, 93-102.

Ballin. R. H. M., and Thomas, P. K. (1969). Changes at the nodes of Ranvier during Wallerian degeneration: an electron microscope study. Acta Neuropathologica (Berlin), 14, 237-249.

Behse. F., and Buchthal, F. (1971). Normal sensory conduction in the nerves of the leg in man. Journal of Neurology, Neurosurgery, and Psychiatry, 34, 404-414.

Behse, F.. Buchthal, F.. Carlsen, F., and Knappeis, G. G. (1972). Hereditary neuropathy with liability to pressure palsies. Brain, 95, 777-794.

Behse, F., Buchthal. F., Carlsen, F., and Knappeis, G. G. (1974). Endoneurial space and its constituents in the sural nerve of patients with polyneuropathy. Brain, 97, 773-784.

Behse, F., Buchthal, F.. Carlsen, F., and Knappeis, G. G. (1975). Unmyelinated fibres and Schwann cells of sural nerve in neuropathy. Brain, 98, 493510.

Behse, F., and Buchthal. F. (1977a). Peroneal muscular atrophy (PMA) and related disorders. II. Histological findings in sural nerves. Brain, 100, 67-85.

Behse, F.. and Buchthal, F. (1977b). Alcoholic neuropathy. Clinical. electrophysiological and biopsy finclings. Annals of Neurology, 2, 95-110.

Bischoff, A. (1965). Die diabetische Neuropathie. Praxis. 54, 723-729.
Bischoff, A. (1968). Diabetische Neuropathie. Pathologische Anatomie, Pathophysiologie und Pathogenese auf Grund elektronenmikroskopischer Untersuchungen. Deutsche Medizinische Wochenschrift, 93, 237-241.

Bischoff, A. (1973). Ultrastructural pathology of peripheral nervous system in early diabetes. In Advances in Metabolic Disorders. Suppl. 2, pp. 441-449. Edited by R. A. Camerini-Dávalos and H. S. Cole. Academic Press: New York and London.

Brown, M. J., Martin, J. R., and Asbury, A. K. (1976). Painful diabetic neuropathy. A morphometric study. Archives of Neurology (Chicago), 33, 164-171.

Buchthal, F., and Rosenfalck, A. (1966). Evoked action potentials and conduction velocity in human sensory nerves. Brain Research, 3, 1-122.

Buchthal, F., Rosenfalck, A., and Behse, F. (1975). Sensory potentials of normal and diseased nerves. In Peripheral Neuropathy, Volume 1, pp. 442-464. Edited by P. J. Dyck, P. K. Thomas, and E. H. Lambert. W. B. Saunders: Philadelphia.

Chopra, J. S., and Hurwitz, L. J. (1969). Sural nerve myelinated fibre density and size in diabetics. Journal of Neurology, Neurosurgery, and Psychiatry, 32, 149-154.

Chopra. J. S., Hurwitz, L. J., and Montgomery, D. A. D. (1969). The pathogenesis of sural nerve changes in diabetes mellitus. Brain, 92, 391-418.

Dyck, P. J., Johnson, W. J., Lambert, E. H., and O'Brien, P. C. (1971). Segmental demyelination secondary to axonal degeneration in uremic neuropathy. Mayo Clinic Proceedings, 46, 400-431.

Fullerton, P. M., Gilliatt, R. W., Lascelles, R. G., and Morgan-Hughes. J. A. (1965). The relation between fibre diameter and internodal length in chronic neuropathy. Journal of Physiology, 178, 26-28P.

Garcin, R., and Lapresle. J. (1968). La microangiopathie du nerf périphérique au cours du diabète sucré. Étude ultrastructurale de biopsies nerveuses et musculaires prélevées dans trois cas de neuropathie diabétique. Bulletins et Mémoires de la Société Médicale des Hôpitaux de Paris, 119, 363381.

Gasser, H. S.. and Erlanger, J. (1927). The role played by the size of the constituent fibres of a nerve trunk in determining the form of its action potential wave. American Journal of Physiology, 80, 522547.

Gilliatt, R. W. (1966). Diabetic neuropathy. In Diabetes mellitus, pp. 64-73. Edited by L. J. P. Duncan. University Press: Edinburgh.

Gilliatt, R. W., and Willison. R. G. (1962). Peripheral nerve conduction in diabetic neuropathy. Journal of Neurology, Neurosurgery, and Psychiatry, 25, 11-18.

Greenbaum, D., Richardson. P. C.. Salmon, M. W., and Urich, H. (1964). Pathological observations on six cases of diabetic neuropathy. Brain. 87, 201-214.

Holländer, H., and Vaaland, J. L. (1968). A reliable staining method for semi-thin sections in experimental neuroanatomy. Brain Research. 10, 120-126. 
Lamontagne, A., and Buchthal, F. (1970). Electrophysiological study in diabetic neuropathy. Journal of Neurology, Neurosurgery, and Psychiatry, 33, 442-452.

Reynolds, E. S. (1963). The use of lead citrate at high $\mathrm{pH}$ as an electron-opaque stain in electron microscopy. Journal of Cell Biology, 17, 208-212.

Sharma, A. K., and Thomas, P. K. (1974). Peripheral nerve structure and function in experimental diabetes. Journal of the Neurological Sciences, 23, 1-15.

Thomas, P. K., and Lascelles, R. G. (1965). Schwanncell abnormalities in diabetic neuropathy. Lancet, 1 , 1355-1357.

Thomas, P. K., and Lascelles, R. G. (1966). The pathology of diabetic neuropathy. Quarterly Journal of Medicine, NS, 35, 489-509.
Thomas, P. K., and Eliassen, S. G. (1975). Sensory potentials of normal and diseased nerves. In Peripheral Neuropathy. Volume 2, pp. 956-981. Edited by P. J. Dyck, P. K. Thomas, and E. H. Lambert. W. B. Saunders: Philadelphia.

Vital, Cl., Vallet, J. M., Leblanc, M., Martin, F., and Coquet, M. (1973). Les neuropathies périphériques du diabète sucré. Étude ultrastructurale de 12-cas biopsiés. Journal of the Neurological Sciences, 18, 381-398.

Vizoso, A. D., and Young, J. Z. (1948). Internode length and fibre diameter in developing and regenerating nerves. Journal of Anatomy (London), 82, 110-134.

Williams, J. R., and Mayer, R. F. (1976). Subacute proximal diabetic neuropathy. Neurology (Minneapolis), 26, 108-116. 